\title{
Educação Ambiental na "Cidade das Fundições": políticas públicas e a configuração do racismo ambiental
}

\author{
Environmental Education in the "City of Foundries": public policies and the configuration of \\ environmental racism
}

Educación ambiental en la "Ciudad de las Fundiciones": políticas públicas y la configuración del racismo ambiental

Recebido: 04/09/2021 | Revisado: 13/09/2021 | Aceito: 17/09/2021 | Publicado: 18/09/2021

\author{
Francisca Marli Rodrigues de Andrade \\ ORCID: https://orcid.org/0000-0001-6450-5911 \\ Universidade Federal Fluminense, Brasil \\ E-mail: marli_andrade@id.uff.br \\ Efrain Francisco Faria \\ ORCID: https://orcid.org/0000-0003-1103-5746 \\ Secretaria de Assistência Social da Cidade de Aperibé, Brasil \\ E-mail: efrain_faria@hotmail.com
}

\begin{abstract}
Resumo
A cidade de Aperibé, no estado do Rio de Janeiro, concentra uma população e dimensão territorial que a situa na categoria socioespacial, denominada pelo IBGE, de "pequeno centro". Entretanto, nessa mesma cidade, o quantitativo de indústrias metalúrgicas de fundição tem crescido expressivamente e, consequentemente, os impactos ambientais dessa atividade econômica. Diante dessa realidade, propomos esta pesquisa que tem como objetivo: analisar a execução das políticas públicas ambientais na cidade de Aperibé-RJ, em especial a Lei $\mathrm{n}^{\circ} 9.795$, de 27 de abril de 1999 - Política Nacional de Educação Ambiental. Metodologicamente, adotamos o enfoque de pesquisa qualitativa, usando entrevistas semiestruturadas enquanto instrumento de coleta de dados. Participaram da pesquisa quatro gestores municipais, vinculados às seguintes secretarias: Secretaria de Educação, Secretaria de Meio Ambiente e Secretaria de Infraestrutura Orçamentária. Os dados da pesquisa foram analisados sob a ótica metodológica da análise do discurso, contemplando três categorias analíticas: a) problemas ambientais - percepções dos gestores municipais; b) fundição - funcionamento das indústrias e geração de emprego e renda; $c$ ) Educação Ambiental - ações e projetos desenvolvidos. Os principais resultados indicam que os representantes das secretarias não consideraram as fundições como provedoras de impactos ambientais. Ademais, muitas das metalúrgicas em funcionamento não atendem às normas de proteção ambiental e de segurança individual dos trabalhadores. Para além disso, os resultados destacam a existência de poucos projetos de Educação Ambiental e a inexistência dos aspectos que discutem os impactos ambientais causados pelo setor de fundição.
\end{abstract}

Palavras-chave Educação ambiental; Cidades das fundições; Políticas públicas; Racismo ambiental.

\begin{abstract}
The city of Aperibé, in the state of Rio de Janeiro, concentrates a population and territorial dimension that places it in the socio-spatial category, called by the IBGE, "small center". However, in that same city, the quantity of metallurgical foundry industries has grown significantly and, consequently, the environmental impacts of this economic activity. Given this reality, we propose this research that aims to: analyze the implementation of public environmental policies in the city of Aperibé-RJ, especially Law N. 9795, of April 27, 1999 - National Policy for Environmental Education. Methodologically, we adopted a qualitative research approach, using semi-structured interviews as a data collection instrument. Four municipal managers participated in the research, linked to the following Municipal Offices: Department of Education, Department of Environment and Department of Budget Infrastructure. The research data were analyzed from the methodological perspective of discourse analysis, covering three analytical categories: $a$ ) environmental problems - perceptions of municipal managers; $b$ ) foundry - operation of industries and generation of employment and income; c) Environmental Education - actions and projects developed. The main results indicate that the representatives of the secretariats did not consider the foundries as providers of environmental impacts. Moreover, many of the metallurgical plants in operation do not meet the standards of environmental protection and individual safety of workers. Furthermore, the results highlight the existence of few Environmental Education projects and the inexistence of aspects that discuss the environmental impacts caused by the foundry sector.
\end{abstract}

Keywords: Environmental education; Foundry cities; Public policy; Environmental racism. 


\begin{abstract}
Resumen
La ciudad de Aperibé, en el estado de Río de Janeiro, concentra una dimensión poblacional y territorial que la ubica en la categoría socioespacial, denominada por el IBGE, "pequeño centro". Sin embargo, en esa misma ciudad ha crecido significativamente la cantidad de industrias de fundición metalúrgica y, en consecuencia, los impactos ambientales de esta actividad económica. Ante esta realidad, proponemos esta investigación que tiene como objetivo: analizar la implementación de políticas públicas ambientales en la ciudad de Aperibé-RJ, en especial la Ley No. 9795, de 27 de abril de 1999 - Política Nacional de Educación Ambiental. Metodológicamente, adoptamos un enfoque de investigación cualitativa, utilizando entrevistas semiestructuradas como instrumento de recolección de datos. En la investigación participaron cuatro gestores municipales, vinculados a los siguientes departamentos: Departamento de Educación, Departamento de Medio Ambiente y Departamento de Infraestructura Presupuestaria. Los datos de la encuesta fueron analizados desde la perspectiva metodológica del análisis del discurso, cubriendo tres categorías analíticas: $a$ ) problemas ambientales - percepciones de los administradores municipales; $b$ ) fundición - explotación de industrias y generación de empleo e ingresos; c) Educación ambiental - acciones y proyectos desarrollados. Los principales resultados indican que los representantes de las secretarías no consideraron a las fundiciones como proveedoras de impactos ambientales. Además, muchas de las plantas metalúrgicas en operación no cumplen con los estándares de protección ambiental y seguridad individual de los trabajadores. De hecho, los resultados destacan la existencia de pocos proyectos de Educación Ambiental y la inexistencia de aspectos que discutan los impactos ambientales provocados por el sector de la fundición.
\end{abstract}

Palabras clave: Educación ambiental; Ciudades de fundición; Políticas públicas; Racismo Ambiental.

\title{
1. Introdução
}

Desde a década de 1970, a Educação Ambiental vem propondo reflexões e questionamentos sobre as desigualdades sociais e econômicas, nas relações que caracterizam as concepções de vida e de existência (Machado \& Moraes, 2019). Essas reflexões e questionamentos têm como base a crítica aos modelos hegemônicos desenvolvimentistas, os quais determinam as relações de apropriação, exploração e comercialização voraz da natureza, com sérios impactos ambientais (Andrade, 2019; 2020). Contrariando tais modelos, a Educação Ambiental interpela o antropocentrismo e, consequentemente “a subordinação da natureza; a fragmentação e a perda da interdependência inerente à existência; o reducionismo e o objetivismo que acabam sacrificando tanto os aspectos não racionais da realidade quanto toda a subjetividade humana" (Lima, 2009, p. 155). O aspecto da interpelação, no contexto da crítica aos modelos desenvolvimentistas, foi o ponto de partida para pensarmos esta pesquisa que tem como objetivo: analisar execução das políticas públicas ambientais, em especial a Política Nacional de Educação Ambiental (PNEA) - Lei No 9.795, de 27 de abril de 1999, na cidade de Aperibé, no Rio de Janeiro.

A pesquisa assume o compromisso de refletir sobre as políticas públicas adotadas para mitigar os impactos ambientais das práticas de metalúrgicas, instaladas na cidade de Aperibé-RJ. Por essa razão, se preocupa em conhecer as práticas de Educação Ambiental, dentro e fora das escolas, entendendo-a como processos, por meio dos quais "o indivíduo e a coletividade constroem valores sociais, conhecimentos, habilidades, atitudes e competências voltadas para a conservação do meio ambiente, bem de uso comum do povo, essencial à sadia qualidade de vida e sua sustentabilidade" (Brasil, 1999). Enquanto aspecto prioritário de investigação, a aplicabilidade da Política Nacional de Educação Ambiental (PNEA) revela-se de extrema importância para o contexto pesquisado, uma vez que as políticas públicas "são a totalidade de ações, metas e planos que os governos (nacionais, estaduais ou municipais) traçam para alcançar o bem-estar da sociedade e o interesse público" (Caldas, 2008, p. 05).

Na pauta das políticas públicas, pesquisas indicam que a Educação Ambiental tem o potencial de propor mudanças estruturais na sociedade, potencializar as práticas e os processos de participação social em defesa do ambiente (Lima, 2009; Machado \& Moraes, 2019; Andrade, 2020). Para Grün (2006, p. 181) a "Educação Ambiental surge no Brasil e no mundo Ocidental de modo geral a partir da constatação de que a educação deveria ser capaz de reorientar as premissas do agir humano em sua relação com o meio ambiente". Isso requer pensar nas inter-relações que, desassistidas de reflexões sobre a importância de todos os componentes do ambiente e de políticas públicas, tem como resultado sérias problemáticas ambientais. Como consequência, as articulações capitalistas protagonizam, cada vez mais, processos de devastação e poluição do ambiente, 
favorecido por um sistema de produção e consumismo desenfreado.

Dentro de uma tendência hegemônica de suposto desenvolvimento, progresso e crescimento, as lógicas capitalistas ampliaram a comercialização da natureza e, assim, desafiam o seu ciclo evolutivo, acelerando uma escalada de problemas ambientais (Porto-Gonçalves, 2006). Muitos desses problemas têm como origem a interferência humana, associada às práticas de comercialização da natureza, intervindo diretamente na relação natureza e sociedade (Porto-Gonçalves, 2006). Desse modo, os problemas ambientais afetam principalmente as classes mais desfavorecidas economicamente, expostas aos riscos e aos impactos eminentes da crise ambiental (Herculano, 2008; Silva, 2012). Nesse jogo de comercialização voraz da natureza, grandes empresas e corporações adotam estratégias diferenciadas para se instalarem em regiões desprovidas e/ou vulneráveis em políticas públicas de fiscalização dos impactos ambientais.

Na pauta da vulnerabilidade, nos Estados Unidos, por exemplo, “a distribuição espacial dos depósitos de resíduos químicos perigosos, bem como a localização de indústrias muito poluentes nada tinham de aleatório" (Herculano, 2001, p. 215), construindo assim uma representação socioespacial, simbólica e física do racismo ambiental. Pois, foi constatado que tais indústrias que operacionalizam suas práticas na "distribuição espacial dos depósitos de resíduos químicos perigosos correspondia e acompanhava a distribuição territorial das etnias pobres" (Silva, 2012, p. 89). Os resultados dessas operacionalizações impactavam nas vidas das populações mais vulneráveis, desassistidas das políticas públicas e abandonadas em localidades comprometidas pela poluição. Isso deixa evidente a forma como a representação socioespacial é determinada pelos processos industriais, uma vez que "as grandes hidrelétricas e as grandes cidades [...] têm um papel de aceleração das relações predatórias entre o homem e o meio, impondo mudanças radicais à natureza” (Santos, 2006, p. 170). Essas relações são fortalecidas em territórios nos quais predominam as desigualdades sociais, reforçando, também, as injustiças ambientais. Contra essas injustiças:

As lutas por justiça ambiental, tal como caracterizadas no caso brasileiro, combinam assim: a defesa dos direitos a ambientes culturalmente específicos - comunidades tradicionais situadas na fronteira da expansão das atividades capitalistas e de mercado; a defesa dos direitos a uma proteção ambiental equânime contra a segregação socioterritorial e a desigualdade ambiental promovidas pelo mercado; a defesa dos direitos de acesso equânime aos recursos ambientais, contra a concentração das terras férteis, das águas e do solo seguro nas mãos dos interesses econômicos fortes no mercado (Acselrad, 2010, p. 114).

As injustiças ambientais transcendem para um racismo ambiental que submete, sobretudo, as classes e os territórios mais vulneráveis a conviverem em determinados lugares poluídos ou desfavorecidos (Silva, 2012). O conceito de racismo ambiental, apresentado nesta pesquisa, ressalta que fica "a maior carga dos danos ambientais do desenvolvimento a grupos sociais de trabalhadores, populações de baixa renda, grupos raciais discriminados, populações marginalizadas e mais vulneráveis" (Herculano, 2006, p. 2). Em todo o Brasil, diariamente, acontecem diversas situações de racismo ambiental. Na cidade de Aperibé, interior do estado do Rio de Janeiro, o grande quantitativo de empresas metalúrgicas e suas práticas de fundição que causam fortes impactos para a população, podem ser considerados como um caso de racismo ambiental.

\section{Perspectivas Contextuais, Teóricas e Metodológicas da Pesquisa}

A pesquisa foca no município de Aperibé-RJ, para analisar a implementação da Política Nacional de Educação Ambiental (PNEA), atravessada pela realidade dos impactos ambientais provocados pelas atividades de fundição. A cidade tem uma população que congrega 11.612 mil habitantes e dispõe de $88,78 \mathrm{~km}^{2}$ com uma forte atividade de indústrias metalúrgicas (IBGE, 2019). Essas indústrias pertencem ao setor de fundição, uma atividade histórica relacionada à modificação da natureza e, por conseguinte, da matéria prima na transformação de peças produzidas por metal, cobre, prata, entre outros metais (Casotti et al., 2011). 
Pensar caminhos alternativos de processos de produção mais limpos é uma tarefa necessária, uma vez que o setor de fundição está diretamente relacionado ao nível de desenvolvimento industrial de um país (Fagundes et al., 2010). Contudo, é importante que esse desenvolvimento esteja associado aos princípios da sustentabilidade e da qualidade do ambiente. $\mathrm{Na}$ cidade de Aperibé, assim como em outros territórios, o setor de fundição também é um grande gerador de impactos ambientais, ao mesmo tempo em que consome um grande nível de bens naturais. Nesse sentido, Bergamo e colaboradores (2012, p. 24) sinalizam que os "principais aspectos e impactos da indústria avaliada corresponderam à emissão atmosférica, ao uso de recursos naturais não renováveis, a deposição de resíduos e situações emergenciais (incêndios, explosões)”. Apresentando, assim, sérios danos e riscos aos territórios nos quais as indústrias atuam. Apesar do setor de fundição possibilitar algumas formas de reaproveitamento de matéria prima, já que "utiliza materiais descartados pela sociedade - objetos metálicos já considerados sucata - como matérias-primas para a constituição dos seus produtos finais" (Fagundes et al., 2010, p. 28), continua a gerar fortes impactos ambientais.

Alguns dos aspectos prejudiciais da fundição está associado ao descarte das areias, as quais são provenientes de uma mistura de matérias usadas no processo de construção das peças. Ao final do processo de fundição, conforme destacado no relatório da Associação Brasileira de Fundição - ABIFA (2008), essa areia contaminada não tem mais utilidade, sendo descartada em aterros; ou seja, uma prática proibida em muitos países, mas que ainda é permitida no Brasil (Fagundes et al., 2010). Para regular a reutilização e descarte dessa areia, em 2007 foi criado o Comitê Brasileiro de Fundição, com a finalidade de instalar a Comissão de Estudos de Areia de Fundição (ABIFA, 2008). Tal comissão "tem como escopo, a normalização referente aos resíduos de fundição, no que concerne a tratamento, utilização, reaproveitamento e armazenamento" (ABIFA, 2008).

Inicialmente, a Comissão de Estudos de Areia de Fundição fez atenção a uma questão prioritária: elaborar uma norma técnica - denominação ABNT NBR 15702:2009 - visando estabelecer as "diretrizes para aplicação de areias descartadas de fundição, como matéria-prima em concreto asfáltico e cobertura diária em aterro sanitário (Fagundes et al., 2010, p. 32). Essas diretrizes são extremamente pertinentes, uma vez que o método mais tradicional de fundição de metais ferrosos no Brasil envolve o uso de moldes confeccionados em areia (Casotti et al., 2011, p. 134). Para além da areia, a poluição do ar e a emissão de gases poluentes configuram como preocupações constantes do setor de fundição que, associada ao consumo de recursos naturais não-renováveis, têm impactado nas mudanças climáticas (Bergamo et al., 2012).

$\mathrm{Na}$ falta da instalação de exaustores para o controle da emissão dos gases, na visão de Bergamo e colaboradores (2012, p. 6), o impacto ao ar fica eminente, considerando que o setor dos Fornos utiliza um grande volume de recursos naturais - água e energia elétrica - na mesma medida em que gera um quantitativo expressivo de gases poluidores. Diante desse cenário, os gestores públicos têm a responsabilidade de fiscalizar os impactos ambientais das instalações industriais na vida da população; bem como, implementar políticas públicas para mitigar tais impactos. Ademais, os gestores públicos devem construir alternativas de diálogos com as comunidades e as empresas, para construir mecanismos de informações sobre os índices e limites de contaminação, conforme previstos nas legislações. Esses mecanismos informacionais podem assumir um papel decisivo na mediação dos conflitos de interesse, já que os crimes ambientais são prescritos em leis que têm como finalidade punir os possíveis responsáveis pelas práticas que possam causar danos ao ambiente.

A Lei n 9.605, de 12 de fevereiro de 1998 - "dispõe sobre as sanções penais e administrativas derivadas de condutas e atividades lesivas ao meio ambiente, e dá outras providências" (Brasil, 1998) - prevê a responsabilidade das instâncias públicas no diz respeito aos crimes ambientais. Entre as condutas sinalizadas encontra-se a omissão de servidores e gestores públicos, no descumprimento da lei e na ausência de implementação de processos de fiscalização, mitigação e informação à população sobre os impactos ambientais. As questões abordadas na Lei no 9.605/1988 e na Política Nacional de Educação Ambiental - Lei no 9.795, de 27 de abril de 1999 - nos auxiliaram a pensar na proposição desta pesquisa. Pois, concordamos 
que a formação crítica da coletividade em Educação Ambiental, "diz respeito a processos educativos reflexivos que problematizam, para compreensão e ação transformadora, as relações sociais de exploração e dominação (Loureiro et al., 2009, p. 86).

A partir da leitura da Educação Ambiental crítica, este estudo foi construído com base no enfoque da pesquisa qualitativa, uma vez que se inscreve no "desafio da compreensão dos aspectos formadores/formantes do humano, de suas relações e construções culturais, em suas dimensões grupais, comunitárias ou pessoais" (André \& Gatti, 2008. p. 4). Com isso, esta pesquisa foi formulada com base nos fundamentos metodológicos do estudo de caso que, na visão de Lüdke e André (1986, p. 18), visa "à descoberta. Mesmo que o investigador parta de alguns pressupostos teóricos iniciais, ele procurará se manter constantemente atento a novos elementos que podem emergir como importantes durante o estudo". Do ponto de vista teórico da pesquisa, adotamos as características do estudo de caso entendendo que "o quadro teórico inicial servirá assim de esqueleto, de estrutura básica a partir da qual novos aspectos poderão ser detectados, novos išnpielementos ou dimensões poderão ser acrescentados, na medida em que o estudo avance" (Lüdke \& André,1986, p. 18). Com base nesses elementos, esta pesquisa qualitativa, focada no estudo de caso, tem como função atender os objetivos propostos neste estudo, ampliando os horizontes interpretativos da forma como as políticas públicas ambientais são gestadas no município de Aperibé-RJ. Para possibilitar um melhor diálogo e reflexão, aplicamos um roteiro de entrevistas semiestruturadas, enquanto instrumento de coleta de dados ${ }^{1}$. O roteiro contemplou, conforme detalhado no Quadro 1, as instituições, as finalidades das secretarias analisadas e perfil dos entrevistados, entre outros:

Quadro 1 - Identificação das secretarias e dos discursos analisados.

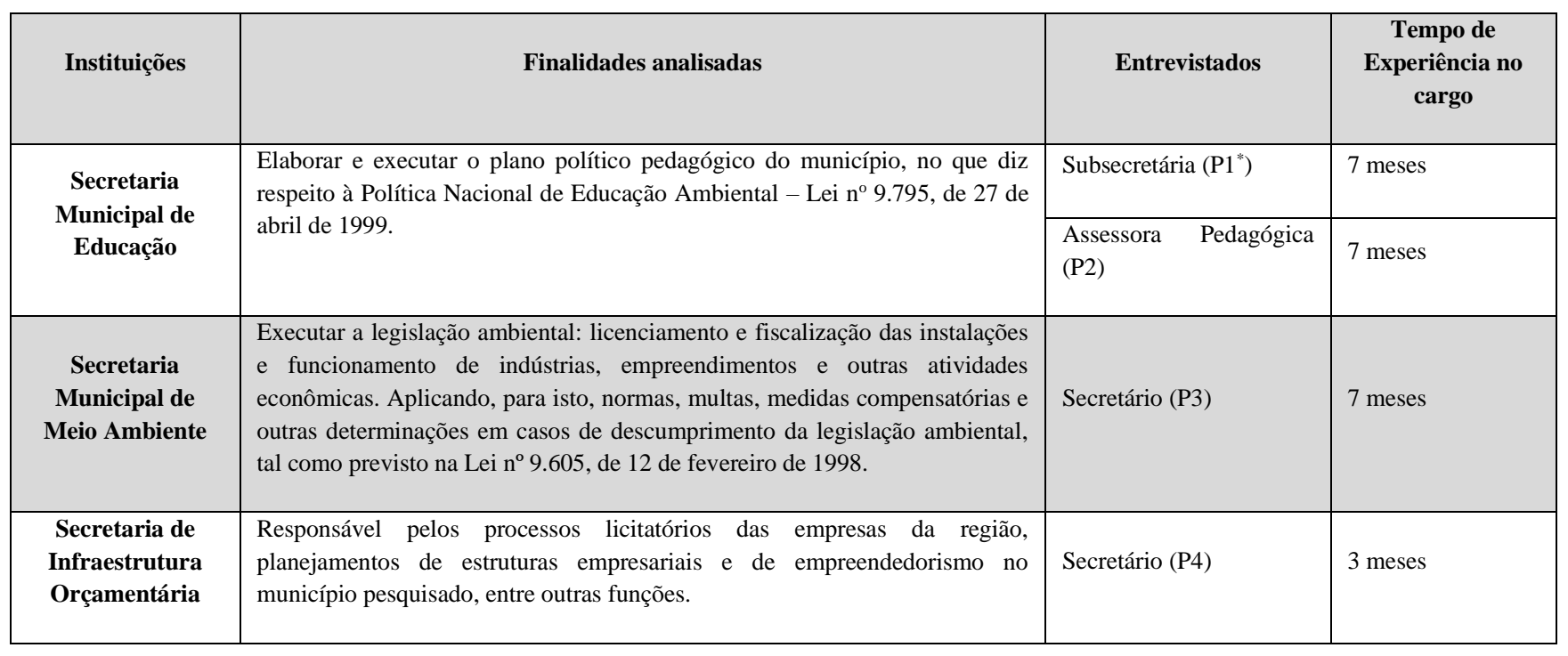

* Código atribuído para identificação das entrevistas.

Fonte: Elaboração nossa. Dados da pesquisa (Outubro, 2019).

As entrevistas foram realizadas no mês de junho de 2019 junto às secretarias citadas, cujas responsabilidades administrativas estão previstas em âmbito legal. Durante essa etapa da pesquisa, entendemos que estávamos dialogando com instâncias responsáveis por executar políticas públicas voltadas ao ambiente, à educação e à estrutura econômica do município. Razão pela qual consideramos importante apresentar um mapa conceitual dos roteiros das entrevistas, com o propósito de possibilitar uma ampla visão dos seguintes aspectos: $a$ ) temas centrais; $b$ ) questões que dialogam entre as secretarias; $c$ )

\footnotetext{
${ }^{1}$ A pesquisa atendeu à todas as exigências éticas e científicas fundamentais, conforme a Resolução nº 466, de 12 de dezembro de 2012 , do Conselho Nacional de Saúde e do Ministério da Saúde.
} 
funcionalidades e finalidades das secretarias. Esse mapa foi pensado de modo a situar os objetivos da pesquisa, as palavras chave da investigação, as categorias de análise elencadas e sua organização interdisciplinar, em perspectiva dialógica. Logo, o mapa indica a forma de apresentação dos resultados, entre outras questões que podem ser observadas na Figura 1.

Figura 1 - Mapa das temáticas contempladas nas entrevistas.

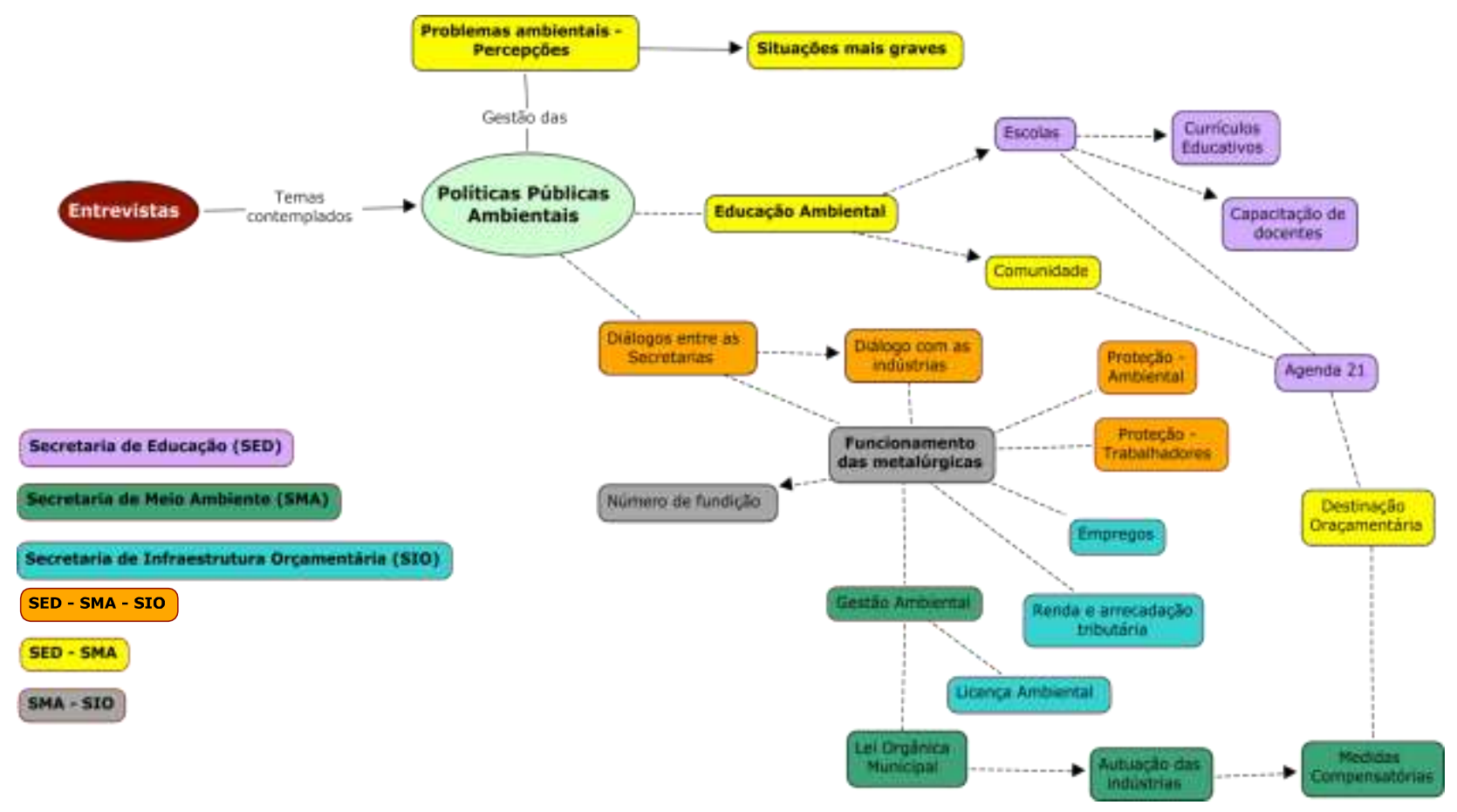

Fonte: Elaboração nossa (2019).

Os roteiros das três entrevistas foram construídos com base no referencial teórico da pesquisa, contemplando os marcos normativos que estabelecem as políticas públicas ambientais e outros dispositivos legais. Entre esses marcos encontrase a Constituição Federal de 1988 e, por conseguinte, no artigo 225 que determina que "todos têm direito ao meio ambiente ecologicamente equilibrado, bem de uso comum do povo e essencial à sadia qualidade de vida, impondo-se ao Poder Público e à coletividade o dever de defendê-lo e preservá-lo para as presentes e futuras gerações" (Brasil, 1988). Esse artigo da Constituição prevê, também, que "§ $1^{\circ}$ Para assegurar a efetividade desse direito, incumbe ao Poder Público: [...] VI promover a educação ambiental em todos os níveis de ensino e a conscientização pública para a preservação do meio ambiente". A partir desse artigo da Constituição, a elaboração dos roteiros das entrevistas foi pensada de modo a facilitar a organização dos dados; isto é, a separação em unidades, a identificação e classificação de unidades e a síntese e o agrupamento, de acordo com o objetivo da pesquisa (Tójar, 2006).

O processo de sistematização das informações facilitou a redução e a organização dos dados, a partir da categorização prévia das perguntas, conforme detalha a Figura 1. Para analisar os dados, adotamos a metodologia de análise do discurso, com o propósito de buscarmos, nos discursos dos entrevistados, as presenças e as ausências sobre as práticas e projetos de Educação Ambiental realizados pela esfera pública na cidade de Aperibé-RJ. Para aplicarmos a análise do discurso - enquanto estratégia metodológica - seguimos as orientações de Andrade (2014, p. 154) que consistem em: "rever todas as notas de campo, as transcrições, documentos e materiais obtidos durante o trabalho empírico; realizar várias leituras com a finalidade de 
familiarizar-se com as informações antes de analisá-las de modo intensivo". Ademais, a autora destaca a importância de "recuperar os segmentos mais significativos e associá-los às concepções teóricas que constituem a pesquisa" (Andrade, 2014, p. 154). Após essas três orientações, adotamos uma análise do discurso orientada pela leitura interpretativa, buscando as relações com o objetivo da pesquisa e os enunciados que atribuem significados aos discursos dos participantes (Fischer, 2001).

\section{Políticas Públicas Ambientais em Aperibé-RJ: percepções, diálogos e práticas em Educação}

\section{Ambiental}

Não somente na cidade de Aperibé-RJ, as metalúrgicas baseiam sua produção no processo de fundir e estão inseridas "na fabricação de peças metálicas por meio do preenchimento, com metal líquido, de um molde cuja cavidade apresenta dimensões similares às da peça que se deseja produzir" (Casotti et al., 2011, p. 122). A prática de fundir é bastante antiga, independente da matéria prima que é usada na produção e "ao longo da Idade do Bronze, com início em torno de 3300 a.C., as técnicas de fundição evoluíram" (Casotti et al., 2011, p. 122). Contudo, os impactos ambientais dessa atividade econômica são severos e estão relacionados à "alteração da qualidade do ar: emissão de gases para a atmosfera, material particulado, odor. Atenção especial é dada aos gases relacionados ao efeito estufa, destruição da camada de ozônio, chuva ácida" (Bergamo et al., 2012, p. 04).

Para mitigar os impactos ambientais provocados pelo setor de fundição, são indispensáveis os marcos regulatórios e as políticas públicas de fiscalização das normas ambientais; bem como, os programas de Educação Ambiental, com a finalidade de construir ações comunitárias voltadas à qualidade ambiental. Diante dessa conjuntura, a análise dos resultados contempla um conjunto de dados que foram estruturados para atender ao objetivo da pesquisa e, portanto, a discussão será realizada a partir de três categorias de análises pré-estabelecidas: a) problemas ambientais - percepções dos gestores municipais de Aperibé - RJ; b) fundição - funcionamento das indústrias e geração de emprego e renda; c) Educação Ambiental na cidade ações e projetos desenvolvidos. Essas categorias foram determinantes para compreendermos e analisarmos os resultados e, por conseguinte, para a construção dos elementos conclusivos desta pesquisa.

\subsection{Problemas ambientais: percepções dos gestores municipais}

Conhecer as percepções sobre problemas ambientais elaboradas pelos representantes das secretarias, no contexto da pesquisa, é importante para compreendermos como os gestores públicos articulam as questões ambientais da cidade. Para isso, buscamos desvelar as principais problemáticas ambientais da cidade na opinião dos entrevistados: "o problema de Aperibé hoje é a coleta seletiva. Ela ainda não foi implantada e não é fácil para ser implantada, porque precisa de uma conscientização muito grande do povo em geral" (P3). Percepções similares foram apresentadas: "eu acho que é a questão do lixo" (P2). Percebe-se uma questão controversa destacada na resposta do P3, quando este participante transmite o fato de não conseguir implementar o sistema de coleta seletiva por culpa da população, a qual não é conscientizada para o projeto. Porém, em conformidade com a Constituição Federal e com a Lei n 9.795, de 27 de abril de 1999, a Educação Ambiental é essencial para o processo de conscientização ambiental, dentro e fora das escolas, não somente para as questões relacionadas à coleta seletiva.

No conjunto dos dados, o saneamento básico foi apresentado como: "temos distritos que não têm saneamento ainda, no loteamento São Caetano, no bairro das Palmeiras, temos a questão do valão que não é coberto" (P1). Encontramos aqui, a existência de outros problemas ambientais: o saneamento básico e o valão que podem promover diversos problemas à saúde da população. Para além da coleta seletiva de lixo e do saneamento básico, é perceptível que nenhum dos entrevistados reconhecem os impactos da fundição como um dos problemas ambientais presentes na cidade. Esses resultados deixam evidente a desatenção ou o silenciamento dessa problemática, uma vez que as práticas de fundição, conforme destacou 
Bergamo e colaboradores (2012), se revelam como grandes geradoras de problemáticas ambientais. Logo, é importante destacar que a fundição "apresenta aspectos e impactos ambientais que devem ser considerados na implantação de um Sistema de Gestão Ambiental” (Bergamo et al., 2012, p. 2).

Quando perguntamos pela problemática ambiental mais grave, apenas um dos participantes ratificou sua resposta dizendo que "eu acho que é saneamento básico" (P2); ou seja, os demais não mudaram de ideia. Isso significa que os entrevistados não reconhecem a dimensão dos impactos das indústrias de fundição e, tampouco, a gravidade desses impactos. Com isso, as entrevistas passaram para o tópico seguinte, justamente para conhecermos as percepções sobre as responsabilidades do poder público municipal. Por essa razão procuramos saber se o município estaria implementando políticas públicas voltadas ao ambiente. Como resultado, foram apresentados apenas dois projetos: "o nosso projeto hoje, é na verdade justamente o que eu acabei de falar, sobre a coleta seletiva. E a coleta do óleo, nós temos projeto para a coleta desse óleo de cozinha, que é um dos resíduos gravíssimos" (P3).

Os dados da pesquisa indicam que o primeiro projeto, voltado à coleta seletiva do lixo, ainda não está em desenvolvimento. O participante na pesquisa destacou que "hoje, um dos projetos que temos é botar em prática a coleta seletiva, não é simplesmente anunciar ou panfletar que tem coleta seletiva e não tem estrutura para receber o lixo" (P3). $\mathrm{O}$ segundo projeto, o qual trata a questão da coleta do óleo de cozinha, funciona apenas "nos grandes geradores, restaurantes $e$ essas coisas assim, mas não é isso que nós queremos, nós queremos fazer do pequeno ao grande" (P3). Com esse discurso, fica evidente que o referido secretário manifestou o desejo de aplicar o projeto da coleta do óleo de cozinha aos "pequenos", dando a entender que se referia aos moradores da cidade. Porém, quando menciona a aplicabilidade desse projeto aos "pequenos" reforça, talvez de forma não intencional, uma fala categórica de racismo ambiental. Em outras palavras, coloca em uma mesma categoria comunidades e atividades comerciais, sem fazer diferenciação da capacidade de poluição entre ambas (Acselrad, 2010; Silva, 2012).

Ademais, o discurso analisado apresenta uma visão pejorativa do Conjunto Habitacional que abriga famílias com baixo poder econômico, principalmente quando o entrevistado considera importante "começar pelas casinhas populares, conscientizar cada um, fazer um projeto de compensação, dar alguma coisa a eles, fazer um sorteio para a coleta". O discurso apresentado deixa evidente uma visão descontextualizada da realidade, ao enfatizar que são as classes sociais com menor poder aquisitivo que mais poluem, colocando como ponto de partida as "casinhas populares". Não menciona as metalúrgicas e seus proprietários, desvinculando a lógica das injustiças ambientais; isto é, classe mais pobre que é frequentemente impactada pelos processos das práticas comerciais, neste caso das metalúrgicas, caracterizando o racismo ambiental (Herculano, 2008). Desde uma perspectiva pedagógica, Paulo Freire (1968) fala das formas focalistas de ação enquanto alienação; isto é...

Quanto mais se pulverize a totalidade de uma área em "comunidades locais", nos trabalhos de "desenvolvimento de comunidade", sem que estas comunidades sejam estudadas como totalidades em si, que são parcialidades de outra totalidade (área, região etc.) que, por sua vez, é parcialidade da totalidade maior (país, como parcialidade da totalidade continental), tanto mais se intensifica a alienação. E, quanto mais alienados, mais fácil dividi-los e mantê-los divididos. Estas formas focalistas de ação, intensificando o modo focalista de existência das massas oprimidas, sobretudo rurais, dificultam sua percepção crítica da realidade e as mantêm ilhadas da problemática dos homens oprimidos de outras áreas em relação dialética com a sua (Freire, 2013, p. 191).

Ainda sobre as políticas públicas ambientais, perguntamos quanto o município destina do seu orçamento para a implementação das mesmas. O participante mencionou que "aqui nós temos um fundo, e o fundo dá para saber porque são três contratos que nós temos aqui, é o que é investido aqui no Meio Ambiente" (P3). Acrescentou que o orçamento da cidade "está em torno de 270.000,00 mil o que é investido hoje no meio ambiente" (P3). Destacou, também, a perda do Imposto sobre Circulação de Mercadorias e Serviços (ICMS) por conta da gestão anterior, o que diminuiu o orçamento. Pois, segundo o 
entrevistado, "hoje nós não temos o ICMS Verde, a gestão anterior deixou de comunicar à época e hoje nós não temos um centavo do Estado que vem de CMS Verde" (P3). Para melhores esclarecimentos, destacamos que o ICMS Verde é visto como:

Uma vertente da política pública conhecida como ICMS Ecológico, que opera uma alteração nos critérios de redistribuição da parcela da receita obtida com a cobrança do imposto sobre operações relativas à circulação de mercadorias e serviços - ICMS - pertencente aos Municípios, com base em elementos ambientais. É considerada como uma aplicação do federalismo fiscal em prol do desenvolvimento socioambiental dos Municípios brasileiros (Merlin \& Oliveira, 2016, p. 277).

A perda do ICMS Verde tem impactos significativos para a receita do município, uma vez que "apenas três contratos vitalizam o orçamento do município voltado às políticas ambientais" (P3). Nesse sentido, as falas dos participantes demonstram uma pluralidade de problemas econômicos e ambientais - com exceção das fundições que não foram consideradas pelos participantes. Com isso, procuramos entender se existe diálogo entre as secretarias na execução das políticas ambientais. Como retorno, tivemos a seguinte resposta: "trabalhamos mais com o pessoal da obra, mais com a secretaria de obra" (P3). Essa parceria se estabelece da seguinte forma: "nós vamos fazer um trabalho de limpeza do bairro de poda e grama, geralmente a obra vai conosco para retirar a parte mais de entulho, que nós não temos a retroescavadeira, que não temos essas coisas assim, essas ferramentas pesadas" (P3).

Os resultados deixam evidente a pouca articulação entre as secretarias, principalmente no que diz respeito à Educação Ambiental. Essa afirmação ganha significado na resposta de outra participante, a qual destacou que "em relação as outras secretarias, ainda não houve um projeto concreto, a gente tem rascunhado, tem articulado conversas, mas...” (P1). Em seguida, mudou a narrativa e disse que "no plantio de muda a secretaria vêm [...] as secretarias estão sempre interligadas e é nesse trabalho unido que estamos conseguindo reerguer o município" (P1). Para além das práticas pontuais, outro participante respondeu que a parceria entre as secretarias "Existe! Pois, todos os processos de permissão de alvará passam pela secretaria de meio ambiente. Todos os que envolve questão ambiental" (P4). Entendemos, nesse discurso, uma relação direta nos processos licitatórios para concessões de alvarás de funcionamento dos estabelecimentos, com a colaboração da Secretaria de Meio Ambiente.

\subsection{Fundição: funcionamento das indústrias e geração de emprego e renda}

A pesquisa no município de Aperibé, estado do Rio de Janeiro, surgiu como uma necessidade ao perceber os processos socioambientais que atravessam a cidade. Principalmente, a relação do município com as indústrias de fundição, uma vez que essas práticas industriais geram impactos ambientais em diferentes perspectivas. Sendo assim, foi perguntado, para mais de um dos entrevistados, qual o número de fundição em pleno funcionamento na cidade. As respostas foram " $n a$ verdade, hoje deve ter em torno de umas 9 fundições" (P3). A primeira resposta nos apresenta números aproximados que o participante acredita ter, enquanto o outro participante disse "18 indústrias" (P4), enquanto apresentava um documento de Relatório de Cadastro de Alvará - Por Atividade, constando o número exato de indústrias registradas e em funcionamento, seus respectivos endereços e o número do processo de concessão de alvará da Prefeitura Municipal de Aperibé-RJ.

A cidade de Aperibé tem uma população e território que a coloca em uma categoria socioespacial, denominada pelo IBGE, como "pequeno centro": 11.612 mil habitantes e 88,78 km² (IBGE, 2019). Estamos falando de um município pequeno, mas com um número proporcionalmente alto de fundições, uma média de 645,1 habitantes por cada uma das indústrias de fundição. Mesmo com esse quantitativo considerável, as metalúrgicas não foram consideradas geradoras de problemas ambientais. Evidências científicas mostram que as fundições são responsáveis por emitir a sílica cristalina respirável, um dos mais graves riscos das fundições. De acordo com Santos e colaboradores (2010), a inalação da sílica cristalina desenvolve doenças respiratórias, como fibronodular intersticial difusa, causadora de vários problemas de saúde 
pública, impactando não somente as comunidades humanas.

Para ressaltar os impactos gerados pelas atividades de fundição, resgatamos o exemplo da cidade de Cubatão-SP, no qual as atividades de fundição geraram graves problemas de saúde, degradando e poluindo o ambiente pelo intenso setor industrial (Juras, 2015). Para melhor entendimento dos impactos que o setor de fundição pode causar, produzimos um mapeamento a partir do território de Aperibé-RJ, com base nos dados do documento Relatório de Cadastro de Alvará - Por Atividade, concedido por um dos participantes na pesquisa. A construção desse mapa, conforme podemos observar na Figura 2, aconteceu por meio da citação das localidades, com base nos endereços de cada Fundição, usando o programa do Google My Maps: Imagery () 2019 Terra Metrics. A função desse mapa é permitir uma visualização da distribuição das 18 indústrias de fundição no espaço territorial de Aperibé-RJ.

Figura 2 - Mapa das Fundições em funcionamento na cidade de Aperibé-RJ.

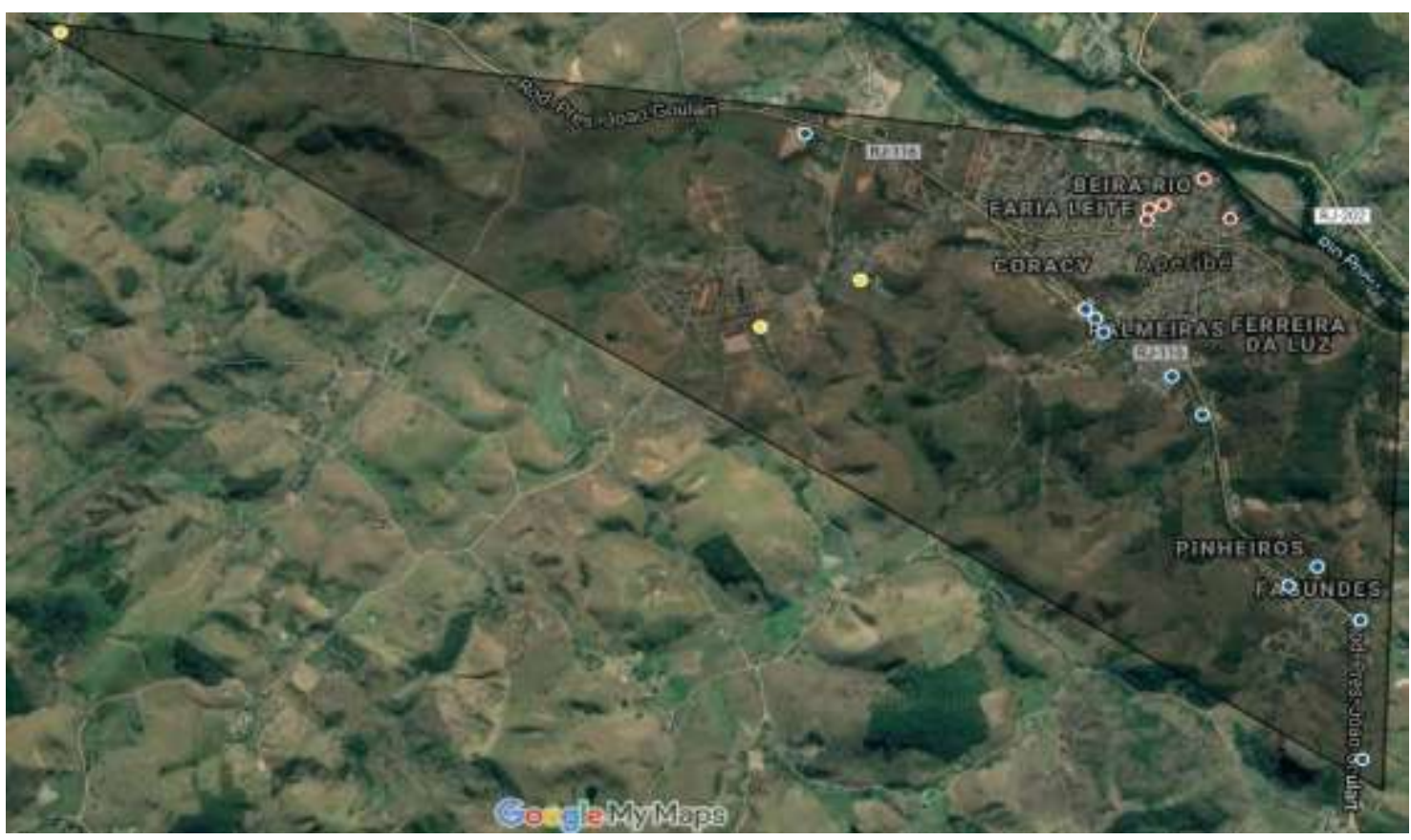

Fonte: Dados da pesquisa. Elaboração nossa (2019).

Como podemos observar na Figura 2, nos bairros Beira Rio e Faria Leite - centro da cidade - estão concentradas 5 metalúrgicas de fundições, com marcador na cor vermelha. No perímetro da Rodovia RJ-116, que corta a cidade, visualizamos cerca de 10 fundições, com o marcador na cor azul - desde os bairros Fagundes e Pinheiros até a Rodovia Presidente João Goulart. Entendemos que a distribuição espacial dessas últimas 10 fundições representa uma logística estratégica, sobretudo para o recebimento de matéria prima e escoamento da produção. O mapa contempla, também, 3 fundições que, com seus marcadores na cor amarela, encontram-se em bairros distantes do centro da cidade. Essas 3 fundições estão localizadas nos seguintes bairros: Ponte Seca, Serrinha e, na parte superior do mapa, uma extensão na área rural denominada Pito Aceso.

Com a elaboração do mapa é possível identificar que as formas do racismo ambiental e suas características, colocam os bairros citados, principalmente os que estão próximos à rodovia que corta a cidade, sob intenso impacto ambiental. O racismo ambiental ocorre, também, nos demais bairros afastados do centro e desprovidos de uma fiscalização. Assim, entendemos que todos os bairros da cidade reúnem as características que nos ajudam a compreender as dinâmicas do racismo ambiental; isto é, a sobreposição dos interesses econômicos ao bem-estar da população (Herculano, 2008; Silva, 2012). Ao 
percebermos tais características, perguntamos aos representantes das secretarias como acontece a relação da gestão ambiental com as indústrias, na interface da Educação Ambiental, sendo respondido que "ainda não tem esse relacionamento" (P3). Admitindo que "eu sei é que hoje falta muita coisa ainda para essas fundições funcionarem 100\% na área ambiental" (P3).

Ademais, o participante P3 mencionou o fato de estarem sendo pressionados pelo Ministério Público (MP) e, com isso, a possibilidade de fiscalização ser passada para o Instituto Estadual do Ambiente do Estado do Rio de Janeiro (INEA). Sobre essa intervenção, o participante destacou que "por coincidência, essa semana teve uma reunião com o Ministério Público, eles me deram 15 dias para eu fazer esse levantamento e tentar chegar em um acordo se a gente vai passar essa fiscalização para o INEIA ou se vai permanecer conosco" (P3). Com isso, não poderíamos deixar de pontuar, a contraditória em admitir que "falta muita coisa ainda, para as fundições funcionarem $100 \%$ na área ambiental". Contudo, quando perguntado pelos problemas ambientais da cidade, as fundições não foram mencionadas.

$\mathrm{O}$ silenciamento dos impactos ambientais das fundições talvez esteja relacionado à percepção de que a cidade vive uma oligarquia das metalúrgicas de fundição, cujos proprietários assumem cargos importantes de representatividade na política local. Essa conjuntura - oligarquia das metalúrgicas de fundição - ganha destaque nos dados da pesquisa, sobretudo diante da não menção dessa atividade comercial e dos problemas ambientais decorrentes dela. Logo, procuramos saber se existe alguma Lei Orgânica Municipal que venha regulamentar as atividades industriais de fundição na cidade, como por exemplo, sobre a emissão de gases poluentes. Como resposta "esse é um dos maiores problemas, e ainda não tem" (P3). Perguntamos, também, se já ocorreu de alguma indústria ser autuada por inflação ambiental "pela Secretaria de Meio Ambiente não [...] estaduais talvez sim, tem os órgãos, batalhão ambiental, Ministério Público mesmo, então eu creio que sim" (P3).

Uma vez mais, o participante P3 demonstra o desconhecimento da gestão ambiental da cidade, o descaso na fiscalização e execução de políticas públicas ambientais, embora esteja há sete meses na gestão da referida secretaria. Esse desconhecimento, de acordo com a Lei $n^{\circ}$ 9.605/1998, pode incidir em sanções penais sobre as condutas administrativas, a depender da sua culpabilidade, uma vez que " o diretor, o administrador, o membro de conselho e de órgão técnico, o auditor, o gerente, o preposto ou mandatário de pessoa jurídica, que, sabendo da conduta crime nossa de outrem, deixar de impedir a sua prática, quando podia agir para evitá-la (Brasil, 2008. p. 237).

Diante do cenário de expansão das práticas industriais de fundição, buscamos saber se existe medidas compensatórias adotadas pelas empresas. Enquanto resultado afirmou-se o seguinte discurso: "se nós não cobrarmos a parte correta delas trabalharem, se a gente não notificar, eles não irão sentir na obrigação de nos dar uma contrapartida. Então ainda não há, não começou ainda isso ẫ" (P3). A fala apresentada retrata a falta de fiscalização no município das medidas de implementação regularizadora que, usando o termo contrapartida, entende-se como uma forma compensação por danos causados. Em conformidade com a Lei federal n ${ }^{\circ}$ 9.985/2000, o empreendedor assume de forma compensatória o pagamento, em caso de identificação dos impactos ambientais. Tais medidas acontecem mediante Estudos de Impacto Ambiental (EIA) e Relatório de Impacto Ambiental (RIMA), conforme destaca o art. 36 da Lei n ${ }^{\circ}$ 9.985, de 18 de julho de 2000; bem como, no art. 31 do Decreto $\mathrm{n}^{\circ} 4.340$, de 22 de agosto de 2002.

As medidas compensatórias não são sinônimas de proteção ao ambiente, pois são formas pagáveis pela poluição e impactos causados que, muitas vezes, não são convertidas em proposta de Educação Ambiental, enquanto tentativa de mitigação e adaptação. Essas medidas são aplicadas de acordo com os processos de licenciamento ambiental, para validação de empreendimentos ou processos de produção. Desse modo, destacamos a Resolução do Conselho Nacional do Meio Ambiente (CONAMA) $n^{\circ}$ 001, de 23 de janeiro de 1986, como fundamental ao processo de identificar o impacto ambiental, com os devidos órgãos de fiscalização. Conforme consta sobre o artigo $2^{\circ}$ da referida resolução, "dependerá de elaboração de estudo de impacto ambiental e respectivo relatório de impacto ambiental - RIMA, a serem submetidos à aprovação do 
órgão estadual competente, e do IBAMA" (Brasil, 1986).

A resolução do CONAMA destaca, em outras palavras, a obrigatoriedade do RIMA para poder executar o procedimento de licenciamento ambiental. De acordo com a Resolução n 237, de dezembro de 1997 do CONAMA, o RIMA é imprescindível para licenciar empreendimento ou atividades que possam ser "consideradas efetiva ou potencialmente poluidoras ou daquelas que, sob qualquer forma, possam causar degradação ambiental” (Brasil, 1997). Os documentos legais citados serviram de base para indagarmos, dentro da proposta de entrevistas, se todas as fundições cadastradas têm licença ambiental municipal para funcionamento. Enquanto resultado, destacamos a seguinte fala: "sim, todas as que estão no cadastro" (P4). De acordo com a resposta, entender que a Secretaria de Meio Ambiente emitiu licença ambiental para as fundições que possivelmente não atendem às normas ambientais, inclusive as normas de emissão de gases poluentes. Razão pela qual, a secretaria está sendo citada pelo Ministério Público (MP).

Ainda sobre as licenças ambientais, quando retrocedemos e resgatamos a resposta sobre existência de diálogo entre as secretarias, esta possibilidade fica mais evidente em função da seguinte resposta: "existem, pois todos os processos de permissão de alvará passam pela secretaria de meio ambiente. Todos os que envolve questão ambiental" (P4). Em resumo, os discursos deixam evidente que a Secretaria de Meio Ambiente tinha informações sobre o quantitativo exato de fundições em funcionamento na cidade, mas houve silenciamento dos impactos ambientais causados por essa atividade econômica. A partir do número de fundição, procuramos saber se esse setor é o principal gerador de renda e arrecadação tributária para a cidade. Os resultados destacam que "minha impressão, como todo, é que sim. Inclusive a cidade é reconhecida como cidade das fundições" (P4).

O discurso "cidades das fundições" retrata o orgulho do participante P3 em relação ao setor econômico. Diante desse orgulho, indagamos quanto as atividades de fundição pagam em impostos; ou seja, quanto representa no orçamento da cidade. Os resultados indicam que "em torno de mais de 25\%" (P4). Ao observarmos com mais atenção os dados da pesquisa, entendemos que esse número - 25\% de arrecadação - é passivo de reflexão e questionamentos, pois se atribuiu um número relativamente baixo, para um setor que é considerado como a maior arrecadação tributária do município, na percepção do P4. Sobre esse tema, lamentavelmente os dados da pesquisa apresentam limitações no que diz respeito ao aspecto tributário, em função das dificuldades de acesso à essas informações. A relevância do valor de arrecadação tributária do setor de fundição para o município, no âmbito da pesquisa, é importante para refletirmos sobre os números que esse setor representa, dado que os empresários desse ramo têm forte influência na gestão das políticas públicas no município.

Em nossa leitura dos dados da pesquisa, a influência dos empresários da fundição na política local revela-se na prevalência dos interesses econômicos, no silenciamento das problemáticas ambientais e na ausência de programas de Educação Ambiental. Por esta razão, buscamos entender, também, se teria dados de quanto o setor da indústria de fundição gera em empregos para a cidade, em resposta o participante proferiu o seguinte discurso: "seria interessante você comparar os números dos cadastros da prefeitura com os das indústrias" (P4). Deixando evidente que alguns dados não seriam disponibilizados para a pesquisa e, portanto, deixando transparecer que existem informações sobre o funcionamento do setor de função que não são de domínio público.

Para além das questões apresentadas, investigamos se existe alguma regularização municipal que fiscalize a questão do uso do Equipamento de Proteção Individual (EPI) pelos trabalhadores. Enquanto resposta, obtivemos: "desconheço qualquer regularização municipal" (P4). Esse discurso sinaliza que, apesar de todos os riscos eminentes que as fundições proporcionam, essa questão não é tratada. Fica evidente o descaso perante os impactos ambientais, uma vez que a atividade de fundição está diretamente relacionada à emissão de gases poluentes e, com isso, impactando na qualidade do ar, na destruição da camada de ozônio, com sérias implicações no fenômeno das mudanças climáticas (Bergamo et al., 2012). Para além desses elementos, os dados revelam, também, os riscos impostos aos trabalhadores que ficam - em detrimento da exposição cotidiana 
ao processamento de rochas ou areia que contenha sílica cristalina - vulneráveis aos problemas de saúde (Santos et al, 2010).

\subsection{Educação Ambiental: entre o conservadorismo e as políticas públicas}

Diante da realidade ambiental da cidade de Aperibé, a pesquisa considerou a relevância da Educação Ambiental, como eixo central e como fonte das práticas pedagógicas voltadas à conscientização crítica, com uma possibilidade de mitigação dos impactos ambientais causados pelas fundições. De acordo com os dados obtidos nas entrevistas com as representantes da Secretaria de Educação, a Educação Ambiental "é trabalhada desde o primeiro ano, a conscientização, projetos e são desenvolvidos durante o ano todo" (P1). Quando perguntamos sobre as temáticas abordadas, as representantes da secretaria destacaram que "tem projetos de lixo, de dengue, do meio ambiente, de água, desde a educação infantil até o nono ano" (P1). Podemos perceber, com esse discurso, uma linha de pensamento que não contempla uma das problemáticas da cidade; ou seja, os impactos das fundições. Sobre esta questão, os resultados identificam que as práticas escolares de Educação Ambiental são construídas nas escolas, sem a interferência da Secretaria de Educação:

Porque inclusive no caso do Ministério Público, não quer que a secretaria imponha um projeto paras as escolas, eles querem que as escolas mandem para gente os trabalhos que eles estão realizando, que não seja imposto nada às escolas, para elas desenvolverem os seus projetos $(\mathrm{P} 2)$.

O discurso apresentado pauta a autonomia das escolas; assim como o olhar e a intervenção do Ministério Público nas ações de Educação Ambiental. As representantes da secretaria mencionaram, também, o trabalho que fazem na Educação de Jovens e Adultos (EJA), envolvendo toda a rede. Destacaram que "esses dias ele (funcionário da escola) fez um trabalho de reciclagem, construir brinquedos utilizando materiais recicláveis, com a professora de arte" (P1). Sobre este projeto, as participantes acrescentaram que "agente propôs para as professoras de arte, esse projeto que estão construindo, eles estão trazendo para mim, para depois estarmos enviando para as creches, para terem esses brinquedos" (P2). Mesmo reconhecendo a importância e o beneficiamento do projeto citado, em subsidiar a partir da reciclagem brinquedos para a creche, entendemos que a Educação Ambiental deve ir além das práticas de reciclagens, incentivar um pensamento crítico que possa questionar os problemas ambientais atuais (Lima, 2009; Machado \& Moraes, 2019).

A Educação Ambiental deve possibilitar reflexões críticas sobre as relações comerciais agressivas da natura, enquanto resultado das interações de todas as dimensões da vida em sociedade (Andrade, 2019). Por esse motivo, resgatamos a ideia dos compromissos que foram firmados na Agenda 21, em relação às questões ambientais e à descentralização desse documento entre as esferas federais, estaduais e municipais. Isto porque, a Agenda 21 Brasileira "é um processo e instrumento de planejamento participativo para o desenvolvimento sustentável e que tem como eixo central a sustentabilidade, compatibilizando a conservação ambiental, a justiça social e o crescimento econômico" (Brasil, 2004). Nesse sentido, perguntamos se a Secretaria de Educação tem articulado uma Agenda 21 para as escolas. Como resposta a participante destacou: "não estamos jogando muito daqui para lá, por causa de cobrança do Ministério Público, que a gente tem um ou outro projeto, mas a maioria é de lá para cá" (P1). Os dados da pesquisa deixam evidentes que o Ministério Público (MP) aparece, constantemente, nas falas dos participantes, na tentativa de fazer valer as leis voltadas à educação relativa à gestão ambiental. Igualmente, a questão da reciclagem é um tema recorrente, pois as entrevistadas enfatizaram que:

No caso de reciclagem das cadeiras velhas que são quebradas, tem um rapaz da obra que faz esse tipo de trabalho aqui, cortou as cadeiras e colocou tampão de madeira, foi enviado para as escolas, para que elas utilizassem junto com os professores de artes e os alunos pintando o banco, para que fizessem toda essa parte de arte e ficou lindo no banco os desenhos deles e frases. Já é uma forma de reciclar (P2). 
As informações da pesquisa enfatizam a ausência de projetos de Educação Ambiental que promovam conscientização crítica nas escolas. Apoiadas no discurso de atender uma demanda do Ministério Público, as entrevistadas entendem que as escolas devem promover os projetos como uma contrapartida para a Secretaria de Educação do município. Simplesmente, uma subversão do que preconiza a Política Nacional de Educação Ambiental (PNEA), a qual entende e propõe autonomia das escolas públicas, mas não isenta as esferas municipais de responsabilidades na execução das políticas públicas, uma vez que estas são de responsabilidade de todas as esferas públicas (Brasil, 1999). Em relação à implementação dessa política pública, indagamos, também, sobre quanto do orçamento da Secretaria Municipal de Educação é destinado à Educação Ambiental; bem como, se os docentes da rede municipal recebem algum tipo de formação continuada nessa área.

As escolas, elas têm uma verba específica que vem diretamente para as escolas que é o PDDE. É o diretor das escolas que gerencia e que mais ou menos, às vezes, compram material, que vem uma cota do que você pode comprar. Eu acredito que não tenha, diretamente assim não (P1).

Os discursos apresentados deixam evidente que não existe, por parte da secretaria, orçamento que seja destinado à Educação Ambiental, mas aponta a utilização de outra verba específica para as escolas - o Programa Dinheiro Direto nas Escolas (PDDE). Isso revela que a cidade não tem uma agenda pensada para mitigar os impactos das práticas de fundição, com o financiamento de verbas específicas desse setor, enquanto recursos de multas e/ou medidas compensatórias voltadas ao desenvolvimento de projetos de Educação Ambiental. A ausência dessa agenda se faz presente nos processos de formação continuada de docente em Educação Ambiental, uma vez que "todo ano, igual agora, a gente já vai para a segunda formação em serviço, então é mais palestras, as vezes surge no meio do assunto, surge outro que as vezes puxa, mas diretamente/diretamente não" (P1).

Outra participante da pesquisa complementou: "agora, recente, vamos ter em relação a informática" (P2). De acordo com os discursos analisados, compreendemos alguns elementos que colocam a Educação Ambiental como uma prática prescindível nas ações educativas, com pouca análise do contexto socioambiental da cidade. Pois, não existem processos de formação de profissionais para a área; assim como o mínimo de incentivo financeiro para se promover a Educação Ambiental no município. No discurso da entrevistada P2, observamos a frustração de tentar amenizar o fato de não existir uma agenda de formação continuada que inclua a Educação Ambiental, mencionando que terá formação na área de "informática". Contudo, essa formação não contempla uma demanda local, na qual a Educação Ambiental é discutida apenas "no meio do assunto" de questões voltadas às outras temáticas.

A realidade da cidade, em meio ao grande número de indústrias de fundição, coloca a necessidade de ampliação das práticas de Educação Ambiental de forma específica, promovendo diálogos que possam incluir as pautas mais complexas que residem nas práticas de racismo ambiental - problemas ambientais, impactos na qualidade de vida, grupos mais afetados, entre outros (Herculano, 2008; Silva, 2012). Nesses diálogos, a Educação Ambiental, nas atividades escolares, precisa ser contemplada. Por isso, perguntamos como funciona a materialização da Educação Ambiental nos currículos educativos. Como resposta, as participantes mencionaram a interdisciplinaridade que consta na Base Nacional Comum Curricular (BNCC), destacando que:

Hoje a BNCC tem essa interdisciplinaridade então você acaba relacionando tudo. Você pode estar trabalhando matemática, é igual semana que vem tem a gincana de matemática na escola, tem algumas das tarefas que acaba voltadas para essa parte. De arrecadação de doação e distribuições, tudo que é arrecadado é distribuído para os asilos, os próprios alunos já vão criando desde pequeno essa conscientização de não desperdiçar água, de apagar a luz não jogar o lixo, então a escola sempre trabalha isso aí (P1).

Mesmo destacando o gesto de solidariedade desenvolvido pela escola, arrecadando e distribuindo subsídios aos 
asilos, ainda não foi possível captar a Educação Ambiental sendo trabalhada de forma a contribuir para uma reflexão crítica sobre os riscos e impactos das fundições. No discurso apresentado está presente um pensamento que não confronta os impactos impostos às comunidades, em detrimento das atividades de fundição. Ademais, os discursos deixam evidente a ausência de uma agenda de trabalho que contemple a Educação Ambiental. Principalmente, quando as representantes da Secretaria de Educação transferem a responsabilidade de um planejamento das práticas de Educação Ambiental para os livros didáticos; isto é, "até os próprios livros didáticos que estão vindo já buscam várias áreas do meio ambiente e de saúde" (P2).

Entendemos que a Educação Ambiental não é apenas pensada para os espaços escolarizados, mas contempla outros segmentos da sociedade. Por isso, perguntamos se teria algum plano de Educação Ambiental que contemple a população, de modo geral. As respostas obtidas destacam que "isso não, diretamente da secretaria para a população não. Isso eu acho que fica mais a cargo do meio ambiente" (P2); ou ainda, "não, que eu saiba não" (P1). Com evidência nos discursos, não existe planos de trabalho em Educação Ambiental que inclua a população; ao contrário, é possível perceber a transferência da responsabilidade para a Secretaria de Meio Ambiente, quando ambas deveriam trabalhar de forma articulada. Nesse sentido, as entrevistadas defendem o argumento que "a educação só participa mais quando tem plantio de mudas, que eles vão em algumas ruas plantar e convidam as crianças, mais essa parte assim" (P2). Com isso, resulta evidente que as concepções de Educação Ambiental que estão sendo pautadas; ou seja, uma concepção distante das problemáticas ambientais enfrentadas pela comunidade.

\section{Algumas Considerações}

A pesquisa partiu da necessidade de compreender, discutir e ampliar o debate sobre as problemáticas socioambientais na cidade de Aperibé-RJ e, portanto, conhecer as políticas públicas que estão gestadas no município. Entre tais políticas voltamos nossa atenção ao funcionamento das metalúrgicas de fundição e à execução da Política Nacional de Educação Ambiental (PNEA) - Lei n ${ }^{\circ}$ 9.795, de 27 de abril de 1999. O propósito de associar essas duas questões consiste em colocar em evidência as problemáticas ambientais da cidade; bem como, ressaltar as possibilidades de conscientização ambiental da comunidade. Em relação à percepção dos problemas ambientais da cidade, os principais resultados indicam que a gestão das políticas públicas ambientais não possibilita a construção de diálogos críticos sobre os problemas ambientais mais recorrentes na cidade. Os representantes das secretarias pesquisadas não consideraram, em momento algum, as fundições como provedoras de grandes impactos ambientais.

Ademais, não foi possível identificar planejamento voltado aos processos de prevenção e mitigação dos impactos causados pelo setor metalúrgico de fundição. Ao contrário, os dados da pesquisa revelam evidências concretas de existência de poucos projetos de Educação Ambiental e ausência dos aspectos que discutem os impactos ambientais causados pelo setor de fundição. No âmbito orçamentário, a cidade de Aperibé dispõe, de acordo com as informações da pesquisa, de um orçamento mensal de 270 mil reais, que é destinado à coleta de resíduos, entulhos e descarte de material hospitalar. Isso significa que o orçamento é direcionado, prioritariamente, para questões de limpeza da cidade, mas não contempla aspectos que possam mitigar outras problemáticas ambientais vivenciadas pela população; como os impactos da intensa atividade de fundição. Essa questão revela-se importante, sobretudo quando as informações da pesquisa sugerem que a falta de qualificação dos profissionais e dos técnicos das secretarias dificulta a realização de projetos de conscientização ambiental.

As perspectivas trabalhadas nas escolas em Educação Ambiental, de acordo com as informações da pesquisa, apresentam-se insuficientes para estimular uma leitura mais profunda dos impactos ambientais, enquanto resultado das atividades de fundição. A relevância desse argumento se consolida se considerarmos que as indústrias metalúrgicas de fundição vêm crescendo de forma acelerada no município. Muitas dessas metalúrgicas, de acordo com os dados da pesquisa, 
não atendem às normas de proteção ambiental e de segurança dos trabalhadores, algo que deveria estar sendo fiscalizado pelo Ministério Público (MP). A ausência de informação sobre os riscos da exposição prolongada às práticas de fundição, não rompe com as lógicas de racismo ambiental instaladas na cidade. Tais lógicas estão intrinsecamente relacionadas ao modelo de produção, aos ganhos econômicos e à exposição de grupos vulneráveis aos impactos ambientais. O silenciamento de algumas situações demonstra um plano de poder para manter, em pleno funcionamento, as práticas comerciais exploratórias dos grupos que ganham com as metalúrgicas de fundição. Pois, os objetivos traçados nas políticas ambientais das três secretarias dialogam com uma visão ambiental conservadora, sem fazer uma análise profundada dos problemas crônicos que afetam a saúde dos morados da cidade. Principalmente esse último aspecto - a saúde dos morados da cidade - apresenta-se como um elemento social e político preocupante, tornando-se uma questão de pesquisa que demanda a nossa atenção nos próximos estudos.

\section{Referências}

ABIFA - Associação Brasileira de Fundição. (2008). ABNT/CB-59 Comitê Brasileiro de Fundição. Revista Fundição \& Matérias-primas, (99a ed.,) São Paulo.

Acselrad, H. (2010). Ambientalização das lutas sociais - o caso do movimento por justiça ambiental. Estudos Avançados, 68(24), 103-119.

Andrade, F. M. R. (2014). Educação Ambiental na Amazônia: um estudo sobre as representações sociais dos pedagogos, nas escolas da rede pública municipal de Castanhal-Pará (Brasil). 582 f. Tese de doutorado. Facultade de Ciencias da Educación, Departamento de Teoría da Educación, Historia da Educación e Pedagoxía Social, Universidade de Santigo de Compostela - España.

Andrade, F. M. R. (2019). Natureza e representações que r-existem: cinco séculos de invasão, apropriação e violência na Amazônia brasileira. Revista Eletrônica do Mestrado em Educação Ambiental, 36(2), 207-227.

Andrade, F. M. R. (2020). Desenvolvimento sustentável na Amazônia brasileira: Significados e conceitos. Arquivos Analíticos de Políticas Educativas, $28(187)$.

André, M., \& Gatti, B. A. (2008). Métodos Qualitativos de Pesquisa em Educação no Brasil: origens e evolução. In: Simpósio Brasileiro-Alemão de pesquisa qualitativa e interpretação de dados. Brasília- DF. 01-13. https://www.uffs.edu.br/pastas-ocultas/bd/pro-reitoria-de-pesquisa-e-pos-graducao/repositorio-dearquivos/arquivos-do-programa-de-formacao/modulo-vii-pesquisa-qualitativa-parte-ii.

Bergamo, B., Tonello, P. S., Medeiros, G. A., \& Ribeiro, A. I. (2012). Avaliação dos aspectos e impactos ambientais de uma indústria de fundição na região metropolitana de campinas. In: Anais do III Congresso Brasileiro de Gestão Ambiental, Goiânia/Go, 19 a 22 de novembro. https://www.ibeas.org.br/congresso/Trabalhos2012/II-004.pdf.

Brasil. (1986). Resolução CONAMA no 001, de 23 de janeiro de 1986. <http://www2.mma.gov.br/port/conama/res/res86/res0186.html>.

Brasil. (1988). Constituição $\quad$ Federal $\quad$ de $\quad$ 1988. $\quad$ Brasília, 2016. <https://www2.senado.leg.br/bdsf/bitstream/handle/id/518231/CF88_Livro_EC91_2016.pdf>.

Brasil. (1997). Resolução CONAMA n $n^{\circ}$ 237, DE 19 DE dezembro DE 1997. <http://www2.mma.gov.br/port/conama/res/res97/res23797.html>.

Brasil. (1998). Lei $n^{\circ}$ 9.605, de 12 de fevereiro de 1998. Dispõe sobre as sanções penais e administrativas derivadas de condutas e atividades lesivas ao meio ambiente, e dá outras providências. Brasília. < http://www.planalto.gov.br/ccivil_03/leis/19605.htm>.

Brasil. (1999). Lei $n^{o}$ 9.795, de 27 de abril de 1999. Institui a Política Nacional de Educação Ambiental. < http://www.planalto.gov.br/ccivil_03/leis/19795.htm>.

Brasil. (2000). Lei $n^{\circ}$ 9.985, de 18 de julho de 2000. Regulamenta o art. 225, § 1o, incisos I, II, III e VII da Constituição Federal, institui o Sistema Nacional de Unidades de Conservação da Natureza e dá outras providências. < http://www.planalto.gov.br/ccivil_03/leis/19985.htm>.

Brasil. (2002). Decreto $n^{\circ} 4.340$, de 22 de agosto de 2002. 2002. Regulamenta artigos da Lei no 9.985, de 18 de julho de 2000 , que dispõe sobre o Sistema Nacional de Unidades de Conservação da Natureza - SNUC, e dá outras providências. <http://www.planalto.gov.br/ccivil_03/decreto/2002/d4340.htm>.

Brasil. (2004). Agenda 21 Brasileira. Ministério do Meio Ambiente. Brasília: MMA<https://antigo.mma.gov.br/responsabilidade-socioambiental/agenda21/agenda-21-brasileira.html>.

Brasil. (2008). Legislação Ambiental Básica. Brasília, DF: Ministério do Meio Ambiente, <http://www.mma.gov.br/estruturas/secex_conjur/_arquivos/108_12082008084425.pd>.

Caldas, R. W. (2008). Políticas públicas: conceitos e práticas. Belo Horizonte: SEBRAE/MG.

Casotti, B. P., Bel Filho, E., \& Castro, P. C. (2011). Indústria de fundição: situação atual e perspectivas. BNDES Setorial, 33, 121-162. https://web.bndes.gov.br/bib/jspui/handle/1408/1721.

Fagundes, A. B., Vaz, C. R., Oliveira, I. L., \& Kovaleski, J. L. (2010). Caminhos para a sustentabilidade do setor de fundição no Brasil. Gepros. Gestão da Produção, Operações e Sistemas, 2, 27-40. https://revista.feb.unesp.br/index.php/gepros/article/view/322. 
Research, Society and Development, v. 10, n. 12, e221101220240, 2021

(CC BY 4.0) | ISSN 2525-3409 | DOI: http://dx.doi.org/10.33448/rsd-v10i12.20240

Fischer, R. M. (2001). Foucault e a análise do discurso em educação. Cadernos de Pesquisa, 114, 197-223.s[ep:

Freire, P. Pedagogia do oprimido. (50ª . ed.): Paz e Terra, 2013.

Grün, M. (2006). A Outridade da Natureza na Educação Ambiental. In: Carvalho, I. C., Grün M., \& Trajber, R. Pensar o Ambiente: Bases filosóficas para a Educação Ambiental. Brasília, 181-189.

Herculano, S. (2001). Justiça Ambiental: de Love Canal à Cidade dos Meninos, em uma Perspectiva Comparada. In: Mello, M. P. (Org.). Justiça e Sociedade: temas e perspectivas. São Paulo: LTr, 215 - 238.

Herculano, S. (2008). O clamor por justiça ambiental e contra o racismo ambiental. Revista de Gestão Integrada em saúde do trabalho e meio ambiente, 3(1), 1-20. http://www3.sp.senac.br/hotsites/blogs/InterfacEHS/wp-content/uploads/2013/07/art-2-2008-6.pdf.

IBGE - Instituto Brasileiro de Geografia e Estatística. (2019). Cidades. https://cidades.ibge.gov.br/brasil/rj/aperibe/panorama.

Juras, I. A. G. M. (2015). Os impactos da Indústria no Meio Ambiente. In: Ganem, R. S. (Org.). Políticas setoriais e meio ambiente. (28a. ed.) Brasília-df: Edições Câmara. Cap. 4, 07-374. < https://www2.camara.leg.br/atividade-legislativa/estudos-e-notas-tecnicas/estudos-por-assunto/tema14>.

Lima, G. F. C. (2009). Educação ambiental crítica: do socioambientalismo às sociedades sustentáveis. Educação e Pesquisa, 35(1), 145-163. http://dx.doi.org/10.1590/S1517-97022009000100010

Loureiro, C. F. B., Trein, E., Tozoni-Reis, M. F., \& Novicki, V. (2009). Contribuições da Teoria Marxista para a educação ambiental crítica. Cad. Cedes, Campinas, 29(77), 81-97.

Lüdke, M., \& André, M. D. A. Pesquisa em Educação: abordagens qualitativas. São Paulo: EPU, 1986.

Merlin, L. V. T., \& Oliveira, A. C. (2016). ICMS verde para a redução do desmatamento amazônico: estudo sobre uma experiência recente. Veredas do Direito, Belo Horizonte, 13(25), 277-306.

Machado, C. R. S., \& Moraes, B. E. (2019). Educação ambiental crítica: da institucionalização à crise. Quaestio - Revista de Estudos em Educação, 21(1), 3958 .

Santos, C. et al. (2010). Silicose - Breve revisão e experiência de um serviço de pneumologia. Revista Portuguesa de Pneumologia, Coimbra, 16(1), 99-115. <http://www.scielo.mec.pt/pdf/pne/v16n1/v16n1a06.pdf>.

Santos, M. (2006). A Natureza do Espaço: Técnica e Tempo. Razão e Emoção. (4ª . ed.): Editora da Universidade de São Paulo.

Silva, L. H. P. (2012). Ambiente e justiça: sobre a utilidade do conceito de racismo ambiental no contexto brasileiro, E-cadernos CES, 17.

Porto-Gonçalves, C. W. (2006). Os (des) caminhos do meio ambiente. (14ª. ed.): Editora Contexto.

Tójar, J. C. (2006). Investigación cualitativa: comprender y actuar: Editorial La Muralla. 